\title{
VDR gene single nucleotide polymorphisms and their association with risk of oral cavity carcinoma
}

\author{
Małgorzata Małodobra-Mazur1', Agnieszka Paduch1', Arleta Lebioda1, Maria Konopacka², Ja- \\ cek Rogoliński², Cezary Szymczyk ${ }^{3}$, Janusz Wierzgoń ${ }^{3}$, Adam Maciejewski³, Ewa Chmielik ${ }^{4}$, \\ Anna Jonkisz', Stanisław Półtorak ${ }^{3}$ and Tadeusz Dobosz ${ }^{1}$
}

'Department of Forensic Medicine, Molecular Technique Unit, Wrocław Medical University, Wrocław, Poland; ${ }^{2}$ Center for Translational Research and Molecular Biology of Cancer Oncology, Maria Skłodowska-Curie Memorial Cancer Center and Institute of Oncology, Gliwice, Poland; ${ }^{3}$ Oncologic Surgery Clinic, Maria Skłodowska-Curie Memorial Cancer Center and Institute of Oncology, Gliwice, Poland; “Tumor Pathology Department, Maria Skłodowska-Curie Memorial Cancer Center and Institute of Oncology, Gliwice, Poland

Vitamin D3 $(1,25(\mathrm{OH}) 2 \mathrm{D} 3$ (1,25-dihydroxyvitamin D3)) is a hormone playing a crucial role in numerous biological processes in the human body, including induction and control of cell proliferation and differentiation. Numerous data relate the vitamin D3 level with various types of cancer. It has been suggested that SNPs in the vitamin D3 receptor (VDR) gene might influence both the risk of cancer occurrence and cancer progression. The aim of this study was to search for genetic correlations between individual SNPs in the VDR gene and the risk of oral cavity carcinoma. Two SNPs were selected based on the literature and our previous results. Seventy-three patients with squamous cell carcinoma of the head and neck and one hundred control subjects were investigated. Two SNPs in the VDR gene were genotyped in minisequencing reactions followed by capillary electrophoresis. Hardy-Weinberg equilibrium (HWE), the $\mathrm{X}^{2}$ test and logistic regression were used for statistical analysis. The SNP rs2238135 in the VDR gene displayed statistical differences in frequency between the tested groups $(p=0,0007)$. Furthermore, the $G / C$ genotype of the rs2238135 in the VDR gene was characterized by a 3.16 fold increased risk of oral cavity carcinoma. The obtained results provide evidence for a genetic association between rs2238135 in the VDR gene and the occurrence and risk of oral cavity cancer.

Key words: oral cavity cancer; SNP; VDR gene

Received: 23 May, 2012; revised: 04 September, 2012; accepted: 17 November, 2012; available on-line: 27 November, 2012

\section{INTRODUCTION}

Vitamin D3 $(1,25(\mathrm{OH}) 2 \mathrm{D} 3)$ is a hormone playing crucial role in numerous biological processes in the human body. More than $50 \%$ of vitamin D3 is synthesized in the human skin from a precursor, 7-dehydrocholesterol (Nussey \& Whitehead, 2001). The main role of vitamin D3 is regulation of calcium metabolism by influencing bones, parathyroid gland, kidneys and intestines (Chung et al., 2009). Furthermore, vitamin D3 affects other organs by inducing and controlling cell proliferation and differentiation (Chung et al., 2009; Molnár et al., 2011).

The crucial stage of vitamin D3 action on targets cell is binding to the vitamin D3 receptor (VDR), belonging to the nuclear receptor family (NR). Human VDR is encoded by the VDR gene located on 12q13-14, composed of 11 exons. Alternative splicing of the VDR transcript results in three isoforms of the receptor. Nuclear receptors act by binding to a specific nucleotide sequence of the promoter region known as response element (RE), which results in transcription activation or inhibition. The DNA binding domain of the VDR gene is encoded by exons 2-4 and has a high affinity to the RE for target genes. The ligand binding domain is encoded by exons 6-9. Binding of vitamin D3 to VDR causes activation of many genes, including those implicated in cell proliferation and differentiation. Therefore vitamin D3 shows pleiotropic effects (Valdivielso, 2009; Kopij \& Rapak, 2008; Field \& Newton-Bishop, 2011).

Apperly in 1941 and Garland in 1980 (Field \& Newton-Bishop, 2011) for the first time suggested a link between the vitamin D3 level and the risk of various cancers. Further results confirmed such a link for numerous cancer types. The most frequently studied were prostate, breast and colon cancers (Field \& NewtonBishop, 2011). Numerous studies suggested a correlation between vitamin D3 concentration and risk of cancer development and progression (Hendrickson et al., 2011; Bertone-Johnson et al., 2005). The anti-cancer activities of vitamin D3 affect cell proliferation (Yang \& Burnstein, 2003), apoptosis induction (Kizildag et al., 2010) and inhibition of angiogenesis and metastasis (Furigay \& Swamy, 2004). Furthermore, vitamin D3 acts as an antiinflammatory agent, which suppresses cancer expansion (Vanoirbeek et al., 2011).

The VDR is essential to mediate all anti-cancer properties of vitamin D3. This has been supported by numerous studies reporting a decreased expression level of VDR gene in cancer cells (Buras et al., 1994) as well as by the association of the VDR polymorphisms with increased risk of multiple cancer types (Holick et al., 2007; McCullough et al., 2009). A great body of literature investigated the association between single nucleotide polymorphisms (SNP) in the VDR gene and the occurrence and frequency of numerous types of cancers (Holick et al., 2007; McCullough et al., 2009). It has been suggested that SNP in the VDR gene might influence both the risk of cancer occurrence and the progression (Köstner et al., 2009; Raimondi et al., 2009). Numerous types of cancers have been correlated with polymorphisms in the VDR gene, mainly breast, prostate, bladder, colon and ovarian

e-mail: maloduszna@yahoo.com

Abbreviations: HWE, Hardy-Weinberg equilibrium; LD, linkage disequilibrium; SNP, single nucleotide polymorphism; VDR, vitamin D3 receptor. 
Table 1. General characterization of the patient group.

\begin{tabular}{llll}
\hline Parameters & Female & Male & Total \\
\hline Number of patients & 25 & 48 & 73 \\
\hline Age & $59(30-83)$ & $57(27-80)$ & 58 \\
\hline Localization of tumors: & & & \\
\hline Squamous cell carcinoma of the oral cavity & & 12 & 17 \\
Ca linquae & 5 & 14 & 19 \\
Ca fundi oris & 5 & 4 & 8 \\
Ca maxillae & 4 & 5 & 10 \\
Ca oropharyngis & 4 & 1 & 2 \\
Ca gingivae mandibulae & 5 & 4 & 4 \\
Ca buccae & 1 & & 1 \\
Ca labii inf & 0 & 0 & 2 \\
\hline Squamous cell carcinoma of the skin & & 2 & 1 \\
Ca auricae sin. & 1 & 1 & \\
Ca cutis capitis & 0 & 0 & \\
Ca reg.submandibularis & & & \\
\hline
\end{tabular}

cancers. However, various studies provided contradictory results (Köstner et al., 2009; Raimondi et al., 2009).

The aim of present paper was to evaluate the influence of two SNPs in the VDR gene (rs2238135 and rs2107301) on cancer development. In our previous study, we showed the correlation between these SNPs and an increased risk of prostate cancer (Forszt et al., 2009). The present paper described results obtained for the same two SNPs correlated with oral cavity cancer.

\section{MATERIALS AND METHODS}

Population description. The study cohort was consisted of seventy-three patients with squamous cell carcinoma of the head and neck diagnosed histopathologically, obtained from the Institute of Oncology in Gliwice. The blood samples were collected after obtaining written consent. General characterization of patients is presented in Table 1. The genetic material of the control group was represented by one hundred samples from male individuals from the Lower Silesian Region, collected in the DNA bank of Molecular Technique Unit, University of Medicine in Wroclaw. The study has been approved by the Ethical Committee in Gliwice.

Single nucleotide polymorphisms characterization. Two SNPs of the VDR gene were investigated. Polymorphisms were selected based on the literature and based on the SNP data base: http://www.ncbi.nlm.nih. gov/ available at NCBI. Furthermore, the choice was supported by our previous study (Forszt et al., 2009). The rs2107301 was located in intron 4 of the VDR gene and the change was the substitution of cytosine by thymine $(\mathrm{C}>\mathrm{T})$. The second polymorphic site rs2238135 was located in intron 1 and the guanine was replaced by cytosine.
Genotyping. Whole venous blood was taken on anticoagulant both from healthy controls and the experimental group after obtaining written consent. DNA was isolated using the QIAamp DNA Mini Kit (Qiagen). DNA fragments were amplified by multiplex PCR using the QIAGEN ${ }^{\circledR}$ Multiplex PCR Kit (Qiagen). Genotyping was performed by multiplex minisequencing using ABI PRISM ${ }^{\circledR}$ SNaPshot Multiplex Kit (Applied Biosystems) according to the manufactur's protocol. The minisequencing products were separated and detected in capillary electrophoresis together with internal size standard GeneScan ${ }^{\text {TM}_{-}}$120LIZ ${ }^{\circledR}$ Size Standard (Applied Biosystems) on ABI PRISM 3130 Genetic Analyzer (Applied Biosytems) and analyzed with the use of GeneMapper ID v3.2 (Applied Biosystems). Results were presented as electropherographs with the fluorescence units (RFU) on the $\mathrm{Y}$ axis and the product size on the $\mathrm{X}$ axis.

Statistical analysis. Statistical significance was considered at $p<0.05$. Differences in SNP frequencies were tested using the $\chi^{2}$ test. Hardy-Weinberg equilibrium (HWE) was established by $\chi^{2}$ test using the following formula $\mathrm{p}^{2}+2 \mathrm{pq}+\mathrm{q}^{2}=1$. Logistic regression analysis was done using STATISTICA8 software, the results were presented as OR with 95\% Cl. Linkage disequilibrium (LD) was assessed using formula $\mathrm{D}=\mathrm{hf}-\mathrm{pi} \times \mathrm{qi}$, (hf-haplotype frequencies, pi, qi — alleles frequencies).

\section{RESULTS}

\section{Hardy-Weinberg equilibrium and linkage disequilibrium analysis}

There was no divergence from Hardy-Weinberg equilibrium for both genotyped SNPs. For both polymorphisms the $\mathrm{p}$ values were established as higher than 0.95 $\left(\chi^{2}\right.$ test). Linkage analysis showed no LD between the two investigated SNPs in the VDR gene.

\section{Genotype frequencies analysis}

The rs2107301 in the VDR gene showed no statistical difference in genotype frequencies $(p=0.2038)$. There was only a slight increase in the $\mathrm{T} / \mathrm{T}$ genotype among patients with oral cavity cancer compared to the control group. The $\mathrm{C} / \mathrm{C}$ and the $\mathrm{C} / \mathrm{T}$ genotypes did not differ between the investigated groups. On the other hand there was a statistically significant difference in genotype frequencies for the rs2238135 between the analyzed groups $(p=0.0007)$. The $\mathrm{G} / \mathrm{C}$ genotype dominated in the experimental group compared to healthy subjects. In

Table 2. The allele and genotype distributions between the investigated groups.

\begin{tabular}{|c|c|c|c|c|c|c|c|c|c|}
\hline \multirow{2}{*}{ rs ID } & \multirow{2}{*}{$\begin{array}{l}\text { Location } \\
\text { in gene }\end{array}$} & \multicolumn{3}{|c|}{ Allele distribution } & \multirow{2}{*}{$p$ value } & \multicolumn{3}{|c|}{ Genotype distribution } & \multirow{2}{*}{$p$ value } \\
\hline & & & Patients & Controls & & & Patients & Controls & \\
\hline rs2107301 & intron 4 & $\begin{array}{l}\mathrm{C} \\
\mathrm{T}\end{array}$ & $\begin{array}{l}0.64 \\
0.36\end{array}$ & $\begin{array}{l}0.69 \\
0.31\end{array}$ & 0.6656 & $\begin{array}{l}C / C \\
C / T \\
T / T\end{array}$ & $\begin{array}{l}0.452 \\
0.384 \\
0.164\end{array}$ & $\begin{array}{l}0.460 \\
0.460 \\
0.08\end{array}$ & 0.2038 \\
\hline rs2238135 & intron 1 & $\mathrm{G}$ & $\begin{array}{l}0.55 \\
0.45\end{array}$ & $\begin{array}{l}0.66 \\
0.34\end{array}$ & 0.4740 & $\begin{array}{l}\mathrm{G} / \mathrm{G} \\
\mathrm{G} / \mathrm{C} \\
\mathrm{C} / \mathrm{C}\end{array}$ & $\begin{array}{l}0.301 \\
0.589 \\
0.11\end{array}$ & $\begin{array}{l}0.51 \\
0.3 \\
0.19\end{array}$ & 0.0007 \\
\hline
\end{tabular}


Table 3. The results of logistic regression for the investigated SNPs.

\begin{tabular}{llll}
\hline rs ID & Genotype & OR $(95 \% \mathrm{Cl})$ & $P$ value \\
\hline rs2107301 & C/C & $1.00($ ref.) & \\
& C/T & $0.68(0.37-1,28)$ & 0.2341 \\
& T/T & $1.2(0.86-5.89)$ & 0.8864 \\
\hline \multirow{3}{*}{ rs2238135 } & G/G & $1.00($ ref.) & \\
& G/C & $3.16(1.67-5.96)$ & 0.0002 \\
& C/C & $0.52(0.21-1.28)$ & 0.1434 \\
\hline
\end{tabular}

the control group the predominat genotype was the wild type homozygote $G / G$. The genotyping analysis is presented in Table 2.

\section{Logistic regression analysis}

The association between individual genotype with increased risk of oral cavity cancer was assessed using logistic regression. An increased odds ratio (OR) was found for the $\mathrm{G} / \mathrm{C}$ genotype of rs2238135 in the VDR gene $(\mathrm{OR}=3.16((1.67-5.96), p=0.0002)$. No further significant association has been found for other genotypes. The logistic regression results are presented in Table 3.

\section{DISSCUSION}

The present paper describes the genotyping results of two SNPs in the VDR gene and their association with the risk of oral cavity cancer. We have shown that the genotype distribution of rs2238135 differed between the investigated groups with significantly higher frequency of the G/C genotype in the experimental group compared to healthy controls. Furthermore, the G/C genotype was characterized by more than 3 fold increased risk of oral cavity carcinoma assessed by logistic regression. No statistically significant difference in genotype distribution was seen for the rs2107301, there was only a slight increase of the $\mathrm{T} / \mathrm{T}$ genotype among patients with oral cavity cancer.

The molecular mechanisms of anti-cancer properties of vitamin D3 mainly affect proliferation (Yang \& Burnstein, 2003) and apoptosis (Kizildag et al., 2010). Vitamin D3 has also been shown to inhibit angiogenesis and metastasis (Furigay \& Swamy, 2004), crucial steps in cancer progression and invasion. Furthermore, vitamin D3 acts as an anti-inflammatory agent, which suppresses the inflammatory process associated with cancer formation (Vanoirbeek et al., 2011). The wide range of anticancer activities of vitamin D3 are exerted by binding to the VDR, which belongs to a class of nuclear receptors. VDR, by binding with a specific nucleotide sequence in the human genome, activates or suppresses expression of multiple genes, including those implicated in carcinogenesis. Furthermore some data provide evidence that vitamin D3 via VDR protects against DNA damage and stimulate the DNA repair, preventing cancer development (Halicka et al., 2012), mainly by attenuation of reactive oxygen species (ROS) and many cytokines and prostaglandins (PG) (Vanoirbeek et al., 2011).

The VDR gene possesses more than 470 single nucleotide polymorphisms that have been extensively studied. The genetic variants have been classified into three blocks: A, B and C depending on LD values. Strong LD can be seen within a block but little LD between blocks (Holick et al., 2007; McCullough et al., 2009). Two SNPs described in this paper belong to block B (rs2107301) and block C (rs2238135) (Holick et al., 2007). As it was mentioned above there is little LD between SNP belonging to various blocks, and, as it was expected, we did not display significant value of LD between analyzed SNP.

Numerous studies linking polymorphisms in the VDR gene with increased risk of many cancer types have been widely published. However, in most cases contradictory results have been presented. The primary reason might be differences in the population origin. There are several studies that reported ethnic variation in the VDR gene polymorphism distribution (Uitterlinden et al., 2004; Zmuda et al., 2000). There are at least 30 papers describing the role of the VDR gene polymorphisms in prostate cancer risk and a dozen papers describing association with colorectal or breast cancers published in the last 30 years (Holick et al., 2007; McCullough et al., 2009). In previous studies investigated SNPs have been correlated mainly with prostate cancer (Holick et al., 2007; Moon et al., 2006; Forszt et al., 2009) as well as with other types of cancers (Uitterlinden et al., 2004). Previously we have described the association between the rs2238135 with prostate cancer with higher frequency of the G/C genotype within experimental groups (Forszt et al., 2009). In the present paper we obtained similar results. The prevalent genotype of the rs2238135 in patients with oral cavity cancer was the $\mathrm{G} / \mathrm{C}$ heterozytes. Moreover, the $\mathrm{G} / \mathrm{C}$ genotype was correlated with a 3.16 fold increased risk of oral cavity cancer. Similar results have been obtained by others (Holick et al., 2007). The second investigated polymorphism rs2107301 did not show significant differences in genotype frequency and did not correlate with increased risk of oral cavity cancer. The results were similar to our previous study (Forszt et al., 2009). There was only a slight increase in the $\mathrm{T} / \mathrm{T}$ genotype among patients compared to controls. Similar results have been obtained by others (Zmuda et al., 2000). On the other hand, some data support the positive correlation between the $\mathrm{T} / \mathrm{T}$ genotype and increased risk of cancers (Holick et al., 2007). Lack of statistical significance in the present paper might be due to too few subjects investigated in this study. Further analysis must be performed to evaluate this issue.

The genetic variants in the VDR gene have been correlated with increased risk of many types of cancers, however, there are just few reports correlating SNPs of the VDR gene with oral cavity cancer (Bektas-Kayhan et al., 2010). Our results for the first time correlated the rs2238135 in the VDR gene with oral carcinoma. The association has been confirmed by OR more than 3 fold increase risk of oral cavity cancer for carriers of the G/C genotype.

Concluding, the obtained results provide evidence for the genetic association between the rs2238135 in the VDR gene and the occurrence and risk of oral cavity cancer.

\section{REFERENCES}

Bektas-Kayhan K, Unür M, Yaylim-Eraltan I, Ergen HA, Toptas B, Hafiz G, Karadeniz A, Isbir T (2010) Association of vitamin D receptor Taq I polymorphism and susceptibility to oral squamous cell carcinoma. In vivo 24: 755-759.

Bertone-Johnson ER, Chen WY, Holick MF, Hollis BW, Colditz GA, Willett WC, Hankinson SE (2005) Plasma 25-hydroxyvitamin D and 1,25-dihydroxyvitamin D and risk of breast cancer. Cancer Epidemiol Biomarkers Prev 14: 1991-1997.

Buras RR, Schumaker LM, Davoodi F, Brenner RV, Shabahang M, Nauta RJ, Evans SR (1994) Vitamin D receptors in breast cancer cells. Breast Cancer Res Treat 31: 191-202.

Chung M, Balk EM, Brendel M, Ip S, Lau J, Lee J, Lichtenstein A, Patel K, Raman G, Tatsioni A, Terasawa T, Trikalinos TA (2009) 
Vitamin D and calcium: a systematic review of health outcomes. Evid Rep Technol Assess (Full Rep) 183: 1-420.

Field S, Newton-Bishop JA. (2011) Melanoma and Vitamin D. Mol Oncol 5: 197-214.

Forszt P, Pilecka A, Malodobra M, Markowska J, Maksymowicz K, Dobosz T (2009) Single-nucleotide polymorphism association study of VDR and CDH1 genes and risk of prostate cancer. Adv Clin Exp Med 18: 215-220.

Halicka HD, Zhao H, Li J, Traganos F, Studzinski GP, Darzynkiewicz Z (2012) Attenuation of constitutive DNA damage signaling by 1,25-dihydroxyvitamin D3. Aging 4: 270-278.

Hendrickson WK, Flavin R, Kasperzyk JL, Fiorentino M, Fang F, Lis R, Fiore C, Penney KL, Ma J, Kantoff PW, Stampfer MJ, Loda M, Mucci LA, Giovannucci E (2011) Vitamin D receptor protein expression in tumor tissue and prostate cancer progression. J Clin Oncol 29: 2378-2385.

Holick CN, Stanford JL, Kwon EM, Ostrander EA, Nejentsev S, Peters U (2007) Comprehensive association analysis of the vitamin D pathway genes, VDR, CYP27B1, and CYP24A1, in prostate cancer. Cancer Epidemiol Biomarkers Prev 16: 1990-1999.

Kizildag S, Ates H, Kizildag S (2010) Treatment of K562 cells with 1,25-dihydroxyvitamin D3 induces distinct alterations in the expression of apoptosis-related genes BCL2, BAX, BCLXL, and p21. Ann Hematol 89: 1-7.

Kopij M, Rapak A (2008) The role of nuclear receptors in cell death. Postepy Hig Dosw 62: 751-581 (in Polish).

Köstner K, Denzer N, Müller CS, Klein R, Tilgen W, Reichrath J (2009) The relevance of vitamin D receptor (VDR) gene polymorphisms for cancer: a review of the literature. Anticancer Res 29: 3511-3536.

McCullough ML, Bostick RM, Mayo TL (2009) Vitamin D gene pathway polymorphisms and risk of colorectal, breast, and prostate cancer. Annu Rev Nutr 29: 111-132.
Molnár F, Sigüeiro R, Sato Y, Araujo C, Schuster I, Antony P, Peluso J, Muller C, Mouriño A, Moras D, Rochel N (2011) 1 $\alpha, 25(\mathrm{OH}) 2-3-$ epi-vitamin D3, a natural physiological metabolite of vitamin D3: its synthesis, biological activity and crystal structure with its receptor. PLoS One; 6: e18124.

Moon S, Holley S, Bodiwala D, Luscombe CJ, French ME, Liu S, Saxby MF, Jones PW, Fryer AA, Strange RC (2006) Associations between G/A1229, A/G3944, T/C30875, C/T48200 and C/ T65013 genotypes and haplotypes in the vitamin D receptor gene, ultraviolet radiation and susceptibility to prostate cancer. Ann Hum Genet 70: 226-236.

Nussey S, Whitehead S. (2001) Endocrinology: An Integrated Approach. pp 65-172. Oxford: BIOS Scientific Publishers, London, UK.

Raimondi S, Johansson H, Maisonneuve P, Gandini S (2009) Review and meta-analysis on vitamin $\mathrm{D}$ receptor polymorphisms and cancer risk. Carcinogenesis 30: 1170-1180.

Uitterlinden AG, Fang Y, Van Meurs JB, Pols HA, Van Leeuwen JP (2004) Genetics and biology of vitamin D receptor polymorphisms. Gene 338: 143-156.

Valdivielso JM (2009) The physiology of vitamin D receptor activation. Contribephrol 163: 206-212.

Vanoirbeek E, Krishnan A, Eelen G, Verlinden L, Bouillon R, Feldman D, Verstuyf A (2011) The anti-cancer and anti-inflammatory actions of $1,25(\mathrm{OH})_{2} \mathrm{D}_{3}$. Best Pract Res Clin Endocrinol Metab 25: 593-604.

Yang ES, Burnstein KL (2003) Vitamin D inhibits G1 to S progression in LNCaP prostate cancer cells through p27Kip1 stabilization and Cdk2 mislocalization to the cytoplasm. J Biol Chem 278: 4686246868.

Zmuda JM, Cauley JA, Ferell RE (2000) Molecular epidemiology of vitamin D receptor gene variants. Epidemiol Rev 22: 203-217. 